\title{
Mechanic Fatally Injured When the Dump Truck Tire He Was Inflating Ruptures - Massachusetts
}

Release Date: February 26, 2018

Investigation: \# 15-MA-030-01
Massachusetts Department of Public Health Occupational Health Surveillance Program

\section{SUMMARY}

On August 13, 2015, a 38-year-old male mechanic (victim) was fatally injured while inflating a truck tire at the maintenance garage of a construction company. The truck was brought back to the company garage location when the driver noticed the truck was leaning to the right. As the victim was inflating the tire with low air pressure, the tire ruptured. The blast of air from the tire rupturing threw the victim 15 feet where he then landed on the ground. The driver of the truck immediately placed a call for emergency medical services (EMS). The local fire department and EMS arrived at the incident location within minutes. The victim was pronounced dead while being transported to the hospital.

Contributing factors identified in this investigation included: not inspecting a tire that had been driven on while underinflated before re-inflation; standing within the trajectory of blast forces while inflating a truck tire; and not training workers about the specific hazards of working with large truck tires and how to identify the hazards associated with filling underinflated truck tires.

The Massachusetts FACE Program concluded that to prevent similar occurrences in the future, employers should:

- Ensure that employees never position themselves in the trajectory of inflated or partially inflated tires while servicing any tire or wheel component;

- Ensure that tires are properly inspected before inflation if they have been driven on while underinflated;

- Ensure that employees are provided with the necessary tools and equipment in order to safely complete any maintenance of truck tires they are expected to perform; and

- Ensure workers are properly trained to identify the hazards of working with large truck tires and are trained in safe procedures for working with tires. 


\section{INTRODUCTION}

On August 17, 2015, the Massachusetts FACE Program was alerted by the Occupational Safety and Health Administration (OSHA) that on August 13, 2015, a worker was fatally injured while inflating a truck tire while working for a construction company. On January 11, 2016, the Massachusetts FACE Program Director and a co-worker traveled to the company's office location and garage. On that visit, they met with a company representative to discuss the incident and view the garage, air compressor, and truck involved in the incident. The police report, death certificate, company information, and the OSHA fatality and catastrophe report were reviewed during the course of the investigation. Photographs were taken of the incident location, compressor, truck, and remaining tires.

\section{EMPLOYER}

The employer is a heavy construction contractor that offers multiple services, including trucking and hauling, heavy equipment rental, and construction demolition material recycling. The company had been in operation for approximately 10 years at the time of the incident. It employed approximately 15 year-round employees, with additional seasonal and summer employees bringing the total to around 40. Three of these employees, including the victim, were mechanics who maintained the trucks and equipment. The victim had initially been hired as a part-time worker and had transitioned to working full-time on the trucks over the summer season.

The typical work hours for the company were 6:00 a.m. to 3:00 p.m. The typical work week was five days per week, and sometimes a half day on Saturdays during the peak summer season. On the day of the incident, the victim was working a normal shift. Some employees, including the lead mechanic who performed equipment maintenance, were represented by a union. Other employees, including the truck drivers, equipment operators, and most mechanics, including the victim, were not represented by a union.

\section{WRITTEN SAFETY PROGRAMS AND TRAINING}

The company did not have a health and safety committee, but did have a written safety program. The program was developed by a contracted workplace safety consulting firm and was stored in the main office. The program covered general workplace safety topics and some of the types of equipment owned and maintained by the company. It did not include details on the hazards of large truck tires and their maintenance. On-the-job training related to the job tasks was provided to employees, but this training did not specifically include workplace safety and health and the training was not provided in Spanish. The company had workers' compensation insurance as required by law in Massachusetts (G.L. c. 152, Sec. 25A).

Preventive maintenance for the trucks, including adding air to low tires, was conducted on-site by the company's mechanics. Each mechanic had their own personal tools at the site. Major repairs to the trucks were performed by a truck dealer. Tire and wheel work was contracted to a few truck tire specialists who typically visited the location a few times each week. The tire specialists typically came to the site after 3:00 p.m. when the trucks would be back at the lot after the end of the work day.

The trucks were reportedly inspected each morning using a Department of Transportation, Federal Motor Carrier Safety Administration checklist in order to check and record general conditions and maintenance issues about the trucks. MA FACE investigators were not able to review records indicating whether the truck had been inspected that morning. The low pressure in the tire involved in 
the incident may not have been identified during a morning check if the truck was not under load and the pusher axle was not in use.

\section{VICTIM}

The victim was a 38-year-old Hispanic male mechanic who had been employed by the company for one and a half years at the time of the incident. He had initially been hired for his welding skills and held a welding certificate in his native country of El Salvador. He helped to maintain the crushing equipment on a part-time basis before transitioning to his full-time position maintaining the trucks. The day of the incident, a Thursday, the victim was scheduled to work a full shift of 6:00 a.m. to 3:00 p.m. The incident occurred around 11:00 a.m., approximately five hours into his shift. The victim spoke Spanish and little to no English, and there were reportedly a limited number of co-workers who could communicate with him in Spanish.

\section{INCIDENT LOCATION}

The incident occurred at the company headquarters that included offices, the truck and equipment lot, maintenance garage, and an area where construction debris was crushed and processed. This location was a mixed industrial and commercial area in a metropolitan community. The site contained many parked trucks and other pieces of heavy equipment that were owned by the company and used for contract work or rental. The garage where the victim worked was accessed through one large bay door on the rear of the building that faced the parking area (Figure 1). The incident occurred just outside the bay door where the truck was parked upon returning for service.

\section{EQUIPMENT}

The vehicle involved in the incident was a tri-axle dump truck manufactured in 2003 (Figure 2). The company owned and maintained six tri-axle dump trucks. The truck involved in the incident was outfitted with tubeless tires mounted on single-piece rims. The tri-axle setup included three axles in the rear: two dual-wheel axles plus a single lift/pusher axle that was located just in front of the tandem dual axles (Figure 3). The lift axle (Figure 4) was activated by the operator of the truck using controls in the cab, and was used to help support a loaded dump bed and assist with stability while turning. The lift axle was powered by compressed air and had controls that regulated and balanced the air pressure balancing the axle. Increasing the air pressure would push the axle downward, putting the tires in contact with the ground to support some of the weight of the load. While the truck was unloaded the lift axle would be in a raised position, keeping the tires a few inches off of the road surface as in Figure 3.

The tire involved in the incident was a tubeless three-and-a half-foot diameter truck tire with a casing consisting of five layers/plies of steel on the tread surface and one layer of steel on the sidewalls. The tire was size 385/65/22.5 with a width of just over 15 inches, and was mounted on a 22.5" single-piece rim. This size tire is wider than the tires mounted on the other axles of the truck. The extra width allows for the tire to support more weight than a standard width tire. When inflated to the recommended max 130 psi this tire was rated to support just over 9,900 pounds. It is unknown if the tire had been original to the truck, but at the time of investigation a tire of a different brand than the tire involved in the incident remained on the opposite side of the axle.

Also involved in this incident was the air compressor used to inflate the truck tire (Figure 5a). This compressor was located inside the garage, near the rear of the maintenance bay. The air supply hose 
was routed from the compressor to nearby the garage bay door, where a coil of hose was stowed (Figure 5b). Additional hose was routed through a hole in the wall of the building (not shown) in order to provide an air supply line outside the garage, next to the fuel pump (Figure 5c). The chuck that was attached to the air supply line was not at the scene at the time of the site visit but photographs were reviewed by FACE investigators. It was a straight dual-head chuck with manual inflation action and was activated by pressing the chuck onto the tire valve. The chuck could not be locked on to the valve and would have required the victim to hold it in position to inflate the tire. The chuck reportedly belonged to the victim, as the mechanics at the company were responsible for supplying most of their own tools.

\section{INVESTIGATION}

The incident occurred around 11:00 a.m. on a Thursday. At the time of the incident it was 77 degrees Fahrenheit, with scattered clouds and a seven mile per hour wind. On the morning of the incident, the driver of the truck involved in the incident had delivered a load of crushed concrete from the yard to a site several miles away and had driven at highway speed. The driver noticed that the truck was leaning to the right side on turns when the lift axle was in use. When he returned to the garage at around 11:00 a.m., after delivering the load, he parked the dump truck outside of the garage near the bay door and reportedly described the issue to the mechanic on duty, the victim. Since the driver did not really speak Spanish, it is unknown if the victim understood that the tire had been driven on.

The victim chocked the wheels of the truck and raised the cab. He then reportedly checked the surface of the tire by touch and proceeded to check the air pressure. The tire was found to be underinflated. The victim proceeded to use the air hose that ran from the compressor in the garage to outside of the garage to add air to the tire. As he was inflating the tire he was standing directly next to the tire. It was reported that the victim's stature compared to the height of the tire meant that his chest was aligned with the sidewall at the top of the tire. As pressure in the tire increased, the sidewall failed near the top of the tire, on the side that was facing away from the truck body. The blast of air struck the victim in the chest throwing him 15 feet. He landed face down on the ground, striking his head.

The truck driver was on the opposite side of the truck, filling the gas tank using the pump that was adjacent to the bay door. He heard the explosion and came around the truck to discover the victim lying face down on the ground. He called 911 and the lead mechanic. The lead mechanic contacted the administrative office to have them also call 911. The town fire department and contracted emergency medical services arrived on scene. The victim was transported to a regional level 1 trauma center where he was pronounced dead on arrival.

\section{CONTRIBUTING FACTORS}

Occupational injuries and fatalities are often the result of one or more contributing factors or key events in a larger sequence of events that ultimately result in the injury or fatality. The Massachusetts FACE team identified the following contributing factors in this incident:

- not inspecting a tire that had been driven on while underinflated before re-inflation

- standing within the trajectory of blast forces while inflating a truck tire

- not training workers about the specific hazards of working with large truck tires

- not identifying the hazards associated with filling underinflated truck tires 


\section{CAUSE OF DEATH}

The medical examiner listed the cause of death as multiple blunt force injuries.

\section{RECOMMENDATIONS/DISCUSSION}

\section{Recommendation \#1: Ensure that employees never position themselves in the trajectory of inflated or partially inflated tires while servicing any tire or wheel component}

Discussion: Large truck tires are a source of hazardous potential energy because of the volume and pressure of the air they contain. If this air pressure is released during a tire or wheel failure, the forces are enough to seriously injure or kill. Depending what part of the tire or wheel fails, the air blast and tire or wheel pieces can project in different directions (Figure 6). Typically when an inflated tubeless tire sidewall fails, the forces will project laterally. For this reason it is important to stay clear of the sidewall of the tire and wheel at all times while performing work on the tire or wheel. This can be done using techniques and tools, such as standing to the front or rear of the tire and using air chucks that can be locked on to the inflation valve. (See Recommendation 3.)

It is likely the sidewall of the tire was compromised when it was driven on under load. With the addition of more air to the tire, the sidewall burst in what is termed a zipper failure. ${ }^{1,2}$ Individual strands in the sidewall of the tire stretched and snapped. This led to increased stress on the adjacent strands and a cascading failure that ripped through the sidewall of the tire, releasing the pressurized air. This type of rupture usually occurs on the top sidewall of the tire as that is the area that undergoes the most stretching when the tire is under load. Because the victim was standing facing the tire, the air blast struck him in the chest.

\section{Recommendation \#2: Ensure that tires are properly inspected before inflation if they have been driven on while underinflated}

Discussion: In this incident, it is unknown if the driver of the truck effectively communicated to the victim that the underinflated tire had been driven on while delivering a load that morning. We do know that the victim did not deflate and inspect the tire for signs of damage and perform a controlled re-inflation of the tire. While the actual low pressure of the tire was not documented, it is believed the pressure was below $80 \%$ of the recommended pressure.

Driving on underinflated, overinflated, or overloaded tires can cause damage to the sidewalls that may not be visible on the outside surface of the tire. Adding air to tires with damaged sidewalls can cause them to fail. For this reason if a tire is driven on while underinflated it is necessary to remove the tire from the rim and conduct a thorough inspection before re-inflating. Recommendations and consensus standards from the Tire and Rim Association, Tire Industry Association, and Rubber Manufacturers Association as well as regulations from OSHA describe that any truck tire that is driven on while it is at less than $80 \%$ of the recommended inflation pressure should be taken out of service and inspected under controlled conditions. ${ }^{3,4,5}$ This includes deflating the tire, removing the valve stem and demounting the tire from the rim, conducting a visual and physical inspection of the tire for defects or signs of damage, and re-inflating the tire in a restraining device and under controlled conditions in order to observe and listen for any signs of failure. This sort of inspection cannot be performed in the 
field, so arrangements would need to be made to swap the underinflated tire for a spare tire or tow the truck to a garage where the tire can be properly inspected.

\section{Recommendation \#3: Ensure that employees have the necessary tools and equipment in order to safely complete any maintenance of truck tires they are expected to perform.}

Discussion: In order to safely inflate large tires, OSHA requires that the inflation device allow the worker to fill a tire while outside of the trajectory of any blast forces (see Recommendation 1). This sort of remote inflation can be accomplished by using a chuck that has the ability to lock onto the valve on the tire. Also required is either a manual inflation valve with a pressure gauge or a regulator that can be set to the desired PSI. These components must be positioned along the air line such that the user can perform the inflation while remaining outside of the dangerous trajectory area, so an extension hose of suitable length is typically connected between the controls and the chuck.

In this incident, the chuck and inflator the victim was using did not meet these requirements. It was reported that the device used by the victim belonged to the victim and came from his own tool set stored at the maintenance garage. It is the norm in some industries for mechanics to supply, maintain, and store their own tools at their place of employment. Because the victim and other mechanics were responsible for maintaining company-owned vehicles and equipment, it is reasonable for the company to supply any specialty tools required to complete their tasks. Whether or not workers supply their own tools, it is important for the employer to ensure that the proper tools are used.

\section{Recommendation \#4: Ensure workers are properly trained to identify the hazards of working with large truck tires and are trained in safe procedures for working with tires}

Discussion: The victim in this incident was not trained on how to properly inspect and inflate tires, nor were the victim or the driver trained to understand that once the tire was driven on while underinflated, it needed to be taken out of service and inspected. Due to the hazards posed by the potential energy stored in large tires, it is important that drivers, mechanics, and other workers be trained to identify and understand this hazard. This applies to any large tire, whether it is on a truck or other heavy or specialized equipment. OSHA standard 1910.177(c) requires that workers be trained and assessed on how to safely service multi-piece and single-piece wheel rims. ${ }^{5}$ It is equally important that workers who service these tires are properly trained on safe procedures and that they understand that tires that have been driven on at $80 \%$ of the recommended inflation pressure or below could be compromised and would need to be removed from service and inspected under controlled conditions before air was added.

All trainings should be performed by a competent person, defined by OSHA as "one who is capable of identifying existing and predictable hazards in the surroundings or working conditions which are unsanitary, hazardous, or dangerous to employees, and who has authorization to take prompt corrective measures to eliminate them." Any training, including but not limited to training on how to perform tasks safely, hazard recognition and avoidance of unsafe conditions, needs to be provided in the employee's preferred language. This means the training must be provided in the language(s) and at the literacy level(s) of the employees. Retraining should be provided for each employee as necessary. In addition, all training should be documented and the documentation should include who provided the 
training and their qualifications, the content of the training, workers who were trained, and the assessments of workers' comprehension of the training.

\section{REFERENCES}

1. Zipper Rupture. Rubber Manufacturers Association, 2011. https://rma.org/wp-content/uploads/ZIPPER-RUPTURE-WALL-CHART.pdf

2. Heavy Vehicles Tire Blowout and Explosion. Instutut de recherché Robert-Sauve en sante et en securite du travail (IRSST), 2009. http://www.irsst.qc.ca/files/documents/PublRSST/R-479.pdf

3. Tire Information Service Bulletin: Inspection procedures to identify potential sidewall "zipper ruptures" in steel cord radial truck, bus and light truck tires. Rubber Manufacturers Association, 2011. https://rma.org/product/tisb-334-inspection-procedures-identify-potential-sidewall-zipper-rupturessteel-cord-radial

4. Code of Federal Regulations, 29 CFR 1910.177, Servicing multi-piece and single piece rim wheels, Motor vehicles, U.S. Government Printing Office.

5. Servicing Single-Piece and Multi-Piece Rim Wheels (booklet). U.S. Department of Labor, Occupational Safety and Health Administration,1998, http://www.osha.gov/Publications/wheel/wheelchart-booklet.pdf

Figure 1 - Truck maintenance garage

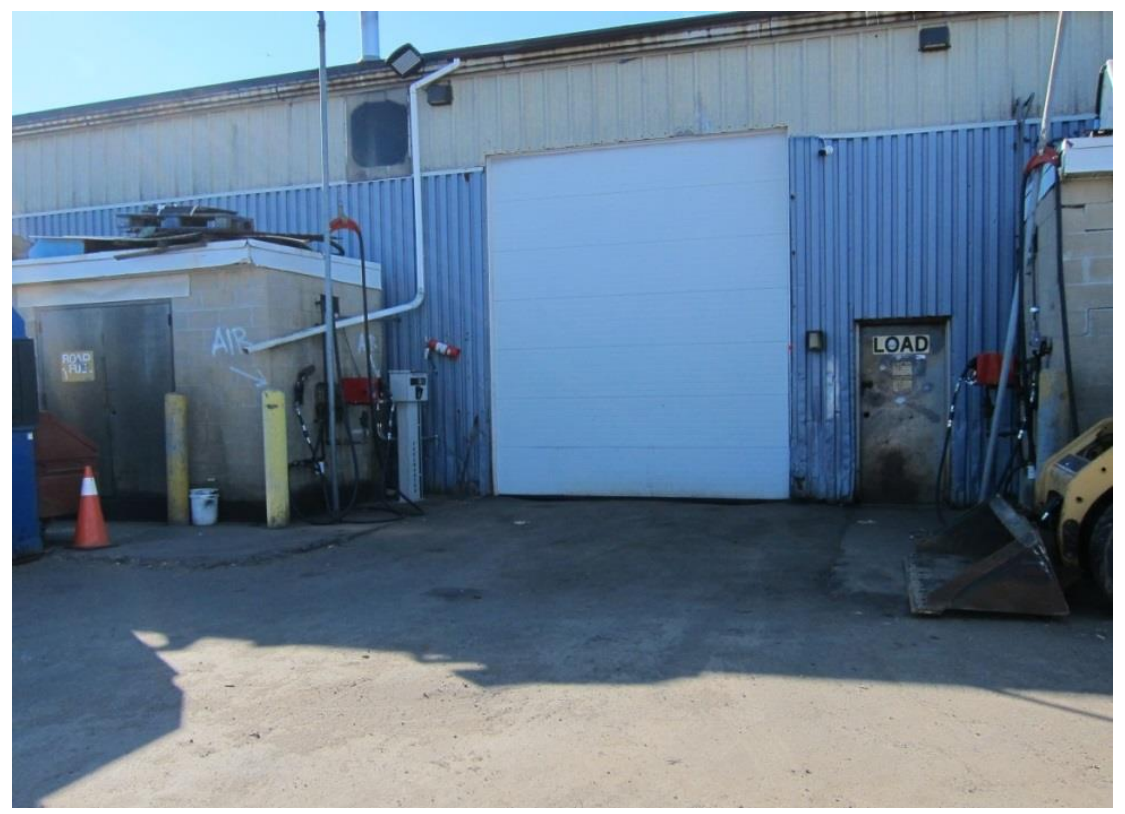


Figure 2 - Truck involved in the incident

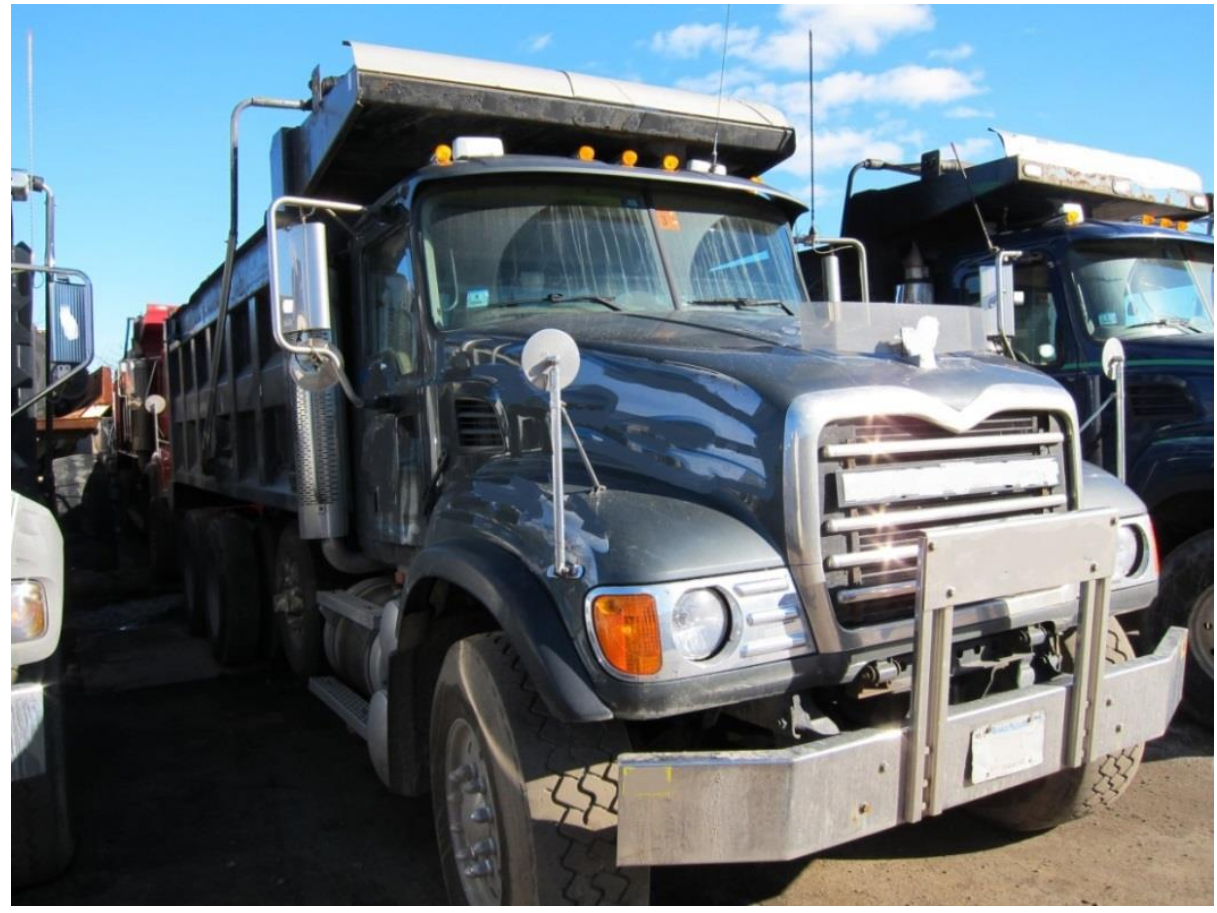

Figure 3 - Tri-axle setup, left side of truck, rear axles

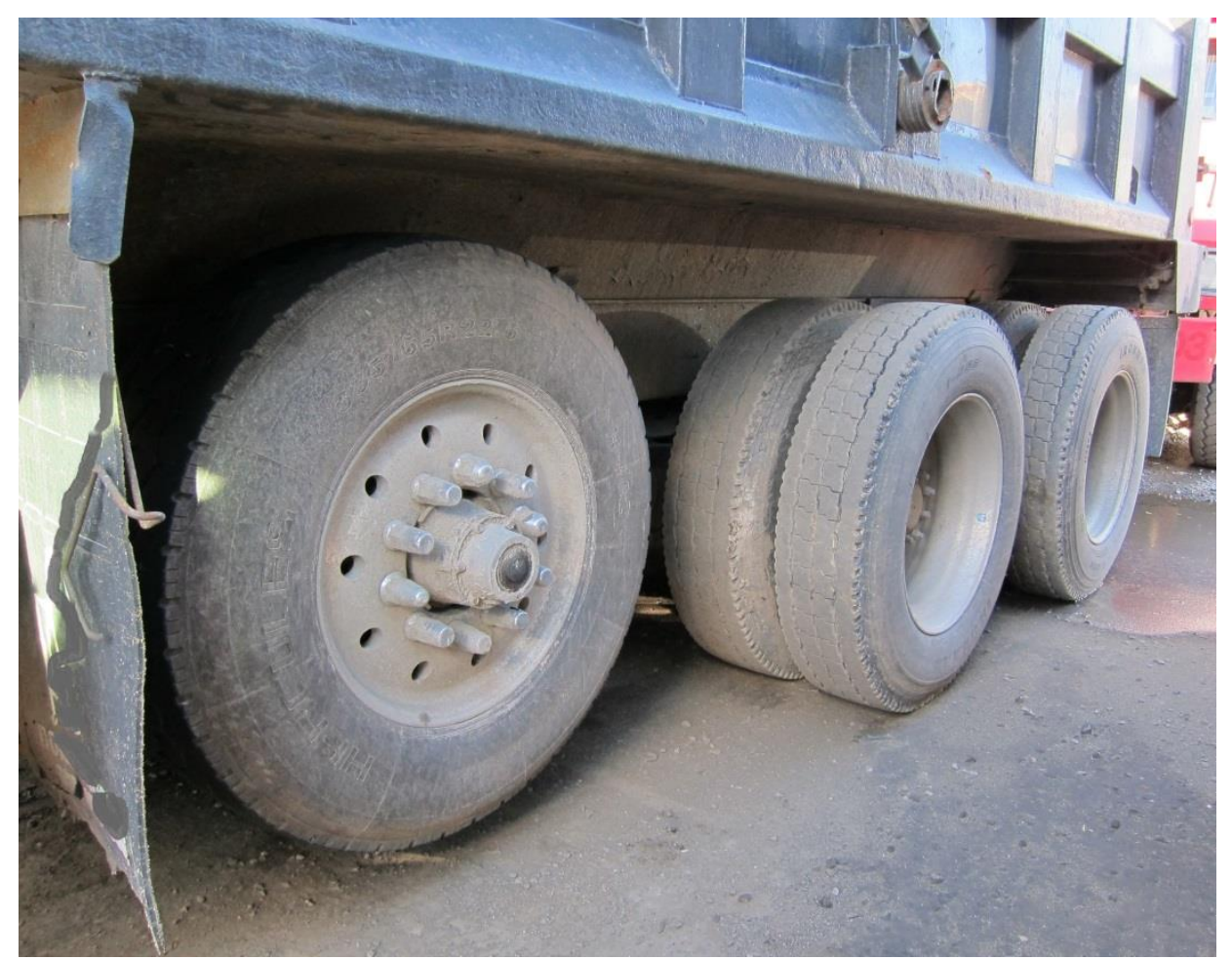


Figure 4 - Lift axle, right side of truck (shown with replacement tire)

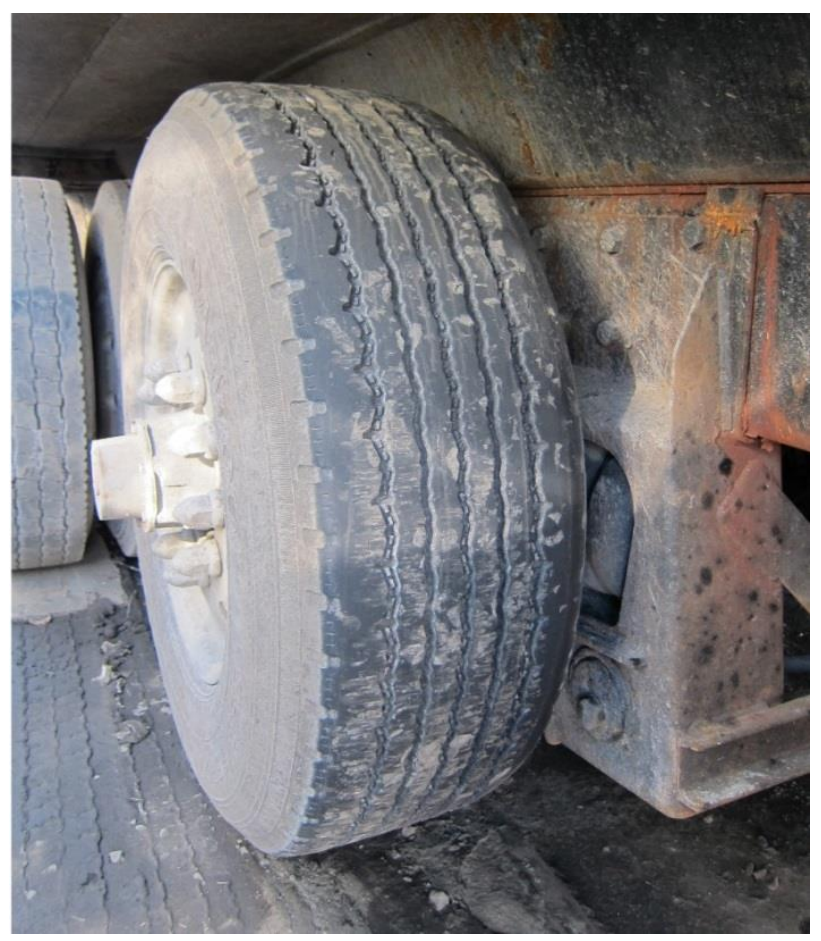

Figure 5a - Air compressor

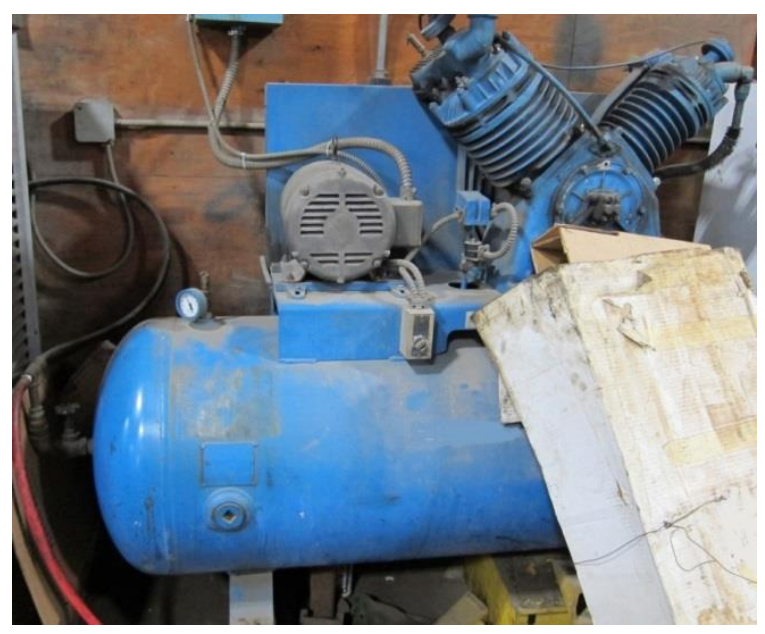

Figure 5b - Air supply line

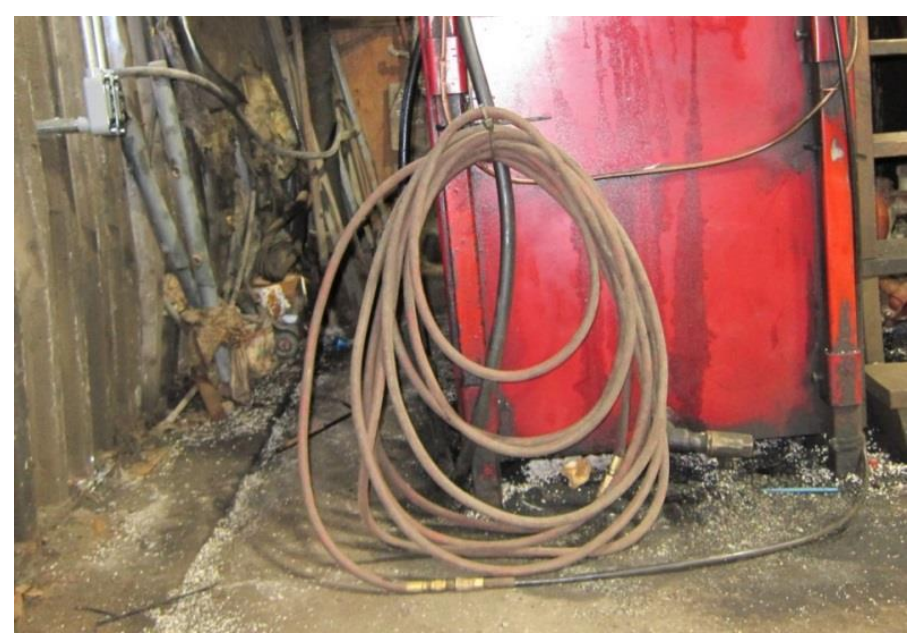


Figure 5c-Location where air hose and chuck were routed through wall of building and stored outside the garage door near the fuel pump

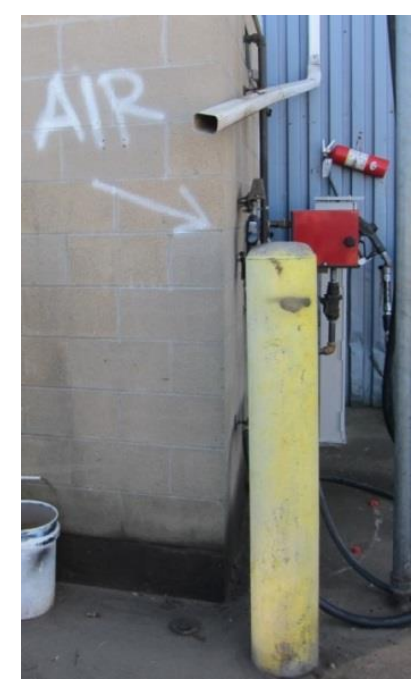

Figure 6 - Trajectory of typical blast forces during tire/wheel failure: tires laid on the ground will direct forces upward; tires on a truck will direct the forces outward from the truck body; unmounted tires will direct forces along the axis of the tire
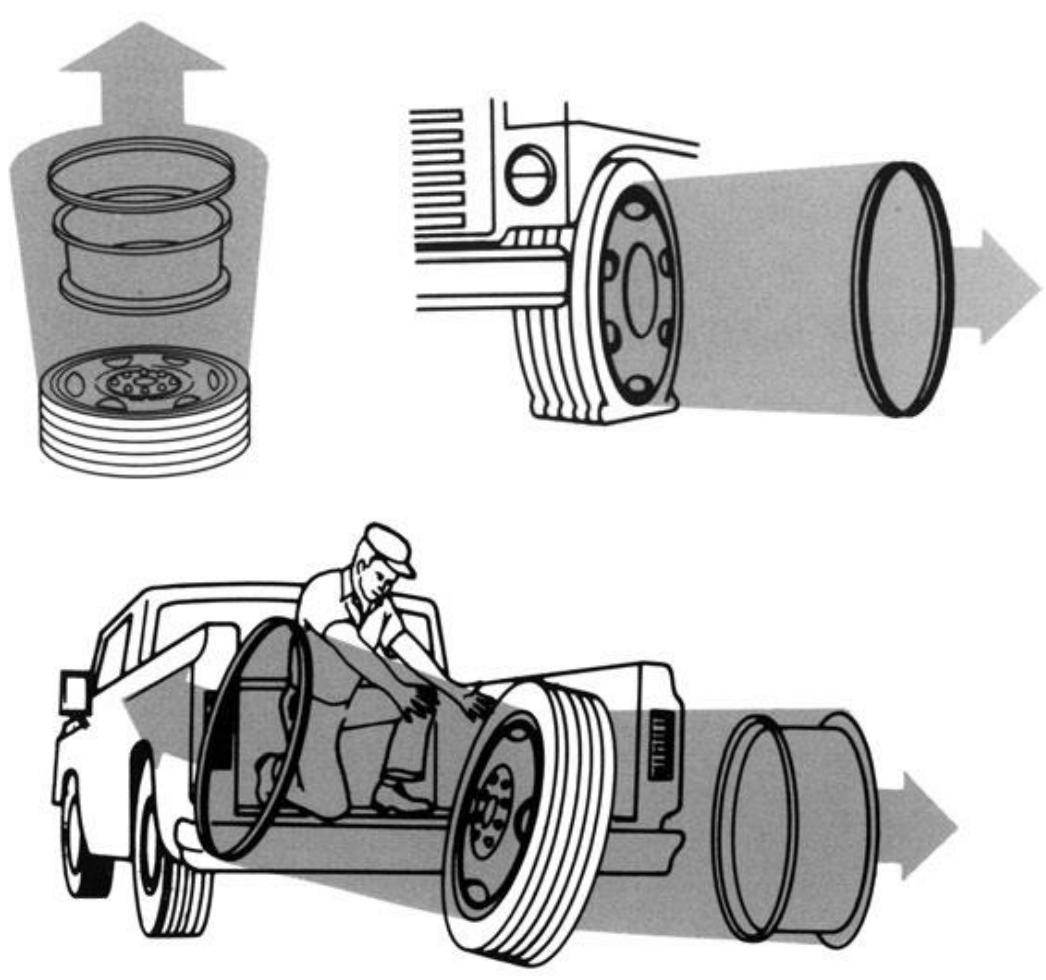